\title{
The effects of forest structure on the risk of wind damage at a landscape level in a boreal forest ecosystem
}

\author{
Hongcheng ZENG ${ }^{1 *}$, Jordi Garcia-Gonzalo ${ }^{2,3}$, Heli PELTOLA $^{2}$, Seppo KeLlOMÄKI $^{2}$ \\ ${ }^{1}$ University of Windsor, Great Lakes Institute for Environmental Research, Windsor, Ontario, N9B 3P4, Canada \\ ${ }^{2}$ University of Joensuu, Faculty of Forest Sciences, 80101 Joensuu, Finland \\ ${ }^{3}$ Centro de Estudos Florestais, Instituto Superior de Agronomia, Technical University of Lisbon, Portugal
}

(Received 9 September 2008; revised version 23 June 2009; accepted 2 July 2009)

Keywords:

critical wind speed /

forest edges /

mechanistic model /

Monte Carlo simulation /

risk of wind damage

Mots-clés :

vitesse critique du vent /

lisières forestières /

modèle mécaniste /

simulation de Monte Carlo /

risque de dommages causés par le vent

\begin{abstract}
- The aim of this work was to analyze how the forest structure affects the risk of wind damage at the landscape level in a boreal forest.

- This was done by employing: (i) Monte Carlo simulation technique for generating landscapes with different age class distributions, proportions of open areas (gaps), and tree species composition; and (ii) a mechanistic wind damage model, HWIND, for predicting the critical wind speeds at downwind stand edges of open areas (gaps) for risk consideration. The level of risk of wind damage observed at the landscape level was significantly affected by the presence of gaps and old stands. Even a slight increase in the proportion of gap areas or older stands had a significant impact on the total length of edges at risk. As a comparison, variation in species composition (Scots pine and/or Norway spruce) had much smaller impact on the risk of damage.

- In conclusion, the effects of forest structure on the risk of wind damage should especially be considered by forest managers in day-to-day forest planning in order to reduce the risk of wind damage both at the stand and landscape level.
\end{abstract}

Résumé - Les effets de la structure de la forêt sur le risque de dommages causés par le vent au niveau du paysage dans un écosystème forestier boréal.

- L'objectif de ce travail était d'analyser comment la structure forestière affecte le risque de dommages causés par le vent à l'échelle du paysage dans une forêt boréale.

- C'est objectif a été atteint par l'emploi : (i) de la technique de simulation de Monte Carlo pour générer des paysages de différentes distributions de classe d'âge, de proportions des zones ouvertes (trouées), et de composition des espèces d'arbres; et (ii) d'un modèle mécaniste de dommages causés par le vent, HWIND, pour la prédiction des vitesses de vent critiques au niveau des lisières sous le vent des zones ouvertes (trouées) en relation avec les risques. Le niveau de risque de dommages causés par le vent observé à l'échelle du paysage a été significativement affecté par la présence de trouées et de vieux peuplements. Une augmentation même légère dans la proportion de trouées ou de vieux peuplements a eu un impact significatif sur la longueur totale des lisières à risque. À titre de comparaison, la variation dans la composition des espèces (pin sylvestre et/ou épicéa) a eu beaucoup moins d'impact sur le risque de dommages.

- En conclusion, les effets de la structure de la forêt sur le risque de dommages causés par le vent devraient être examinées en particulier par les gestionnaires forestiers pour une planification des opérations forestière au jour le jour, afin de réduire le risque de dommages causés par le vent à la fois au niveau du peuplement et au niveau du paysage.

\section{INTRODUCTION}

Wind-induced damage is a continuous cause of economic loss in managed forests throughout the world. For example, in Europe about 180 million $\mathrm{m}^{3}$ of timber was damaged by

*Corresponding author: zenghc@uwindsor.ca wind during storms in December 1999 (UNECE/FAO, 2000). Similarly, in Finland over 7 million $\mathrm{m}^{3}$ of timber were affected by storms that occurred in November 2001 (Pellikka and Järvenpää, 2003).

Wind-induced damage can significantly change the structure and functioning of a forest ecosystem. It can, for example, increase the fragmentation of forests and thus, also the 
Table I. Number of inventoried forest stands in each age class in a boreal forest.

\begin{tabular}{|c|c|c|c|c|c|c|c|c|c|c|}
\hline Stand group & \multicolumn{2}{|c|}{ Sapling stands } & \multicolumn{2}{|c|}{ Before first thinning } & \multicolumn{3}{|c|}{ Thinning stands } & \multicolumn{3}{|c|}{ Mature stands } \\
\hline Age class & $<10$ & $11-20$ & $21-30$ & $31-40$ & $41-50$ & $51-60$ & $61-70$ & $71-80$ & $81-90$ & $>90$ \\
\hline Number of Norway spruce stands & 25 & 124 & 145 & 146 & 143 & 178 & 224 & 264 & 273 & 345 \\
\hline
\end{tabular}

amount of vulnerable edges. As a result of wind damage, broken and uprooted trees left in the forest can also lead to detrimental insect attacks on the remaining trees, because of an increase in breeding sites (Ravn, 1985). Therefore, an improved understanding of the vulnerability of forests to wind damage is needed to help foresters to manage the wind related risks through forest planning.

The susceptibility of trees and forest stands to wind damage is controlled not only by the properties of wind (i.e. wind speed, duration, and gustiness; see Mayer, 1989), but also by the tree and stand characteristics, such as tree species, tree height, tree diameter, crown area, rooting depth and width, and stand density (Coutts, 1986; Gardiner et al., 1997; Peltola et al., 1999; 2000). Moreover, large differences in the risk of wind damage can be observed between regions and locations that differ in topography and wind climate (Copeland et al., 1996; Quine, 2000). For example, forests located on hills or higher altitudes are, on average, the most susceptible to damage (Talkkari et al., 2000).

On the other hand, prevailing landscape structure (e.g. species composition and configuration) also affects the resistance of individual tree stands to wind damage. For example, the presence of gaps in fragmented forests increase the wind speeds, especially high-speed winds, at the downwind stand edges (Venäläinen et al., 2004). The wind flow is, however, significantly reduced within the stand about 1-2 tree heights downwind of the stand edge (Peltola et al., 1999), and the adjustment is essentially completed by about 10 tree heights inside the stand from the edge (McNaughton, 1989). The occurrence of wind damage has also complicated the reciprocal effects regarding forest structure. For example, as a consequence of salvage cuttings after wind damage, new open areas (gaps) are created, which will modify the forest structure and landscape configuration, and thus also affect the risk of damage.

Despite many previous studies on the risks of individual tree stands to wind damage, it is not yet clearly understood how the risk of wind damage is affected at the landscape level by the prevailing forest structure (e.g. landscape composition and configuration) and by the changes occurring to the forest structure over time. This is at least partly because the tree and stand characteristics of individual tree stands and their changes over time affect, together with wind flow over the terrain, the overall risk of forests at the landscape level. However, improved understanding of the effects of forest structure on the risk of wind damage could assist forest managers to make better decisions in order to manage forest resources minimizing risk of wind damage.

In recent years, mechanistic wind damage models have been developed (Ancelin et al., 2004; Gardiner et al., 2000; Peltola et al., 1999). These models can simulate the wind flow at forest edges and within tree stands as well as predict the threshold wind speeds (i.e. critical wind speeds) needed for trees to be uprooted or broken (Peltola et al., 1999). This enables the systematic studying of the risk of wind damage in forest ecosystems with different forest structures. For this purpose, geographical information system (GIS) can also provide the topological relationship between neighboring polygons (forest stands), and polygons and arcs (forest edges). Thus, information regarding neighboring polygons and length of boundaries make it possible to calculate the edges of forest stands with risk of wind damage using vector forest data (i.e. polygons and arcs) as alternative to raster data.

In the above context, the aim of this work was to analyze how the forest structure affected the risk of wind damage in terms of length of stand edges at risk at the landscape level. For this purpose, we first generated landscapes with different age class distributions, proportions of mature stands and open areas (gaps), and tree species composition, based on stand inventory data available from a boreal forest ecosystem located in central Finland. Thereafter, HWIND, a mechanistic wind damage model (Peltola et al., 1999), was applied to predict the critical wind speeds needed to uproot or break the trees at downwind edges of open areas (gaps) of the generated landscapes in order to provide basis for risk considerations at the landscape level. Our study site is relatively flat in topography, and therefore the influence of topography was excluded in the analyses.

\section{MATERIAL AND METHODS}

\subsection{Landscape construction}

As a basis for generating different kinds of landscapes, we used stand inventory data (i.e. tree and stand characteristics such as average tree height, breast height diameter and stand density) available from a boreal forest ecosystem located in central Finland $\left(63^{\circ} 01^{\prime} \mathrm{N} ; 27^{\circ} 48^{\prime} \mathrm{E}\right)$. In total, 551 Scots pine (Pinus sylvestris) and 1867 Norway spruce (Picea abies) stands were classified into 4 different age class groups (i.e. sapling stands $>2 \mathrm{~m}$ in height, first thinning age stands, older thinning stands, and mature stands ready for regeneration, see Tab. I). In our work each age class group consisted of 2 or 3 age classes. All these stands were used as alternatives in the Monte Carlo simulation, which randomly selected forest stands for constructing landscapes with different forest structures, following the approach used earlier by Garcia-Gonzalo et al. (2007). Open areas (i.e. gaps) in this study were defined as water areas, agricultural fields, clearcuts and seedling stands $(<2 \mathrm{~m}$ in height); they were also automatically generated by the simulation program. The landscape used for analysis 
Table II. The proportion of area of total forest area (gaps and seedlings stands $<2 \mathrm{~m}$ in height excluded) in each age class group in a boreal forest ecosystem for different age class distributions of a landscape.

\begin{tabular}{lcccc}
\hline $\begin{array}{l}\text { Age class } \\
\text { distribution }\end{array}$ & $\begin{array}{c}\text { Sapling stands } \\
(<20 \mathrm{y})\end{array}$ & $\begin{array}{c}\text { Before first thinning } \\
(21-40 \mathrm{y})\end{array}$ & $\begin{array}{c}\text { Thinning stands } \\
(41-70 \mathrm{y})\end{array}$ & $\begin{array}{c}\text { Mature stands } \\
(>70 \mathrm{y})\end{array}$ \\
\hline Normal & $25 \%$ & $30 \%$ & $30 \%$ & $15 \%$ \\
Equal & $25 \%$ & $25 \%$ & $25 \%$ & $25 \%$ \\
Left-skewed & $50 \%$ & $25 \%$ & $15 \%$ & $10 \%$ \\
Right-skewed & $10 \%$ & $15 \%$ & $25 \%$ & $50 \%$ \\
\hline
\end{tabular}

consisted of 2108 polygons, with a corresponding area of 3081 ha.

The landscapes were first constructed according to the two main factors affecting the risk of wind damage at the landscape level; i.e. the proportion of gap area and age class structure of the forest. In the analyses we used relative gap areas ranging from $10 \%$ to $70 \%$ of the total area (with an interval of $10 \%$ ). Correspondingly, forests with different age class structures ranged, thus, from 90 to $30 \%$ of the total area. Altogether, we studied four forest structures based on the distribution of age class groups: normal distribution, equal distribution, left-skewed and right-skewed distribution (see Tab. II). Within each age class, the forest also had an equal distribution of Scots pine and Norway spruce stand areas (each 50\%).

We also assessed how sensitive the risk of damage is to the proportion of older (mature) stands in a forest. This was done because in Finnish conditions older stands have been found to be most vulnerable to be damaged by wind, especially if they are located at newly created forest edges (Peltola et al., 1999; Zeng et al., 2004). For this purpose, we used the equal age class distribution as a reference, and changed the proportion of mature stands by $\pm 15 \%$ (i.e. alternatively into $40 \%$ or $10 \%$ ) and decreased other age classes equally to keep the sum as $100 \%$ of the total forest (i.e. other age class groups still equally had $20 \%$ or $30 \%$ of total forest areas). The area of open gaps was fixed at $30 \%$ of the total landscape area.

In order to evaluate the risk of wind damage, with regard to species composition, we also changed the proportion of Scots pine and Norway spruce by $\pm 15 \%$ in the forest landscape with the normal age class distribution, which is closer to the preferred distribution in Finnish forest management units. Thus, the share of tree species used was $65 \%$ for Scots pine and $35 \%$ for Norway spruce, and vice versa.

In the process of generating forest landscapes, each stand polygon was randomly defined as a gap, or a forest stand (Fig. 1). Consequently, the forest stand was further randomly classified into an alternative age class, and tree species (Scots pine or Norway spruce). All these random processes were weighted by the area of each age class so that the landscape had the designed proportion of gap areas, species composition and the desired age class distribution (i.e. normal, equal, left-skewed or right-skewed distribution). Since vector polygons were used in this study, there existed small differences between the final total area of each age class group and the desired area. However, as the studied landscape has a large area (3081 ha with 2108 stand polygons), the difference was very small and had little influence on the final results.
In addition to the proportions of the gap area, age class structure and tree species composition of the forest, some other factors may also affect the risk of wind damage at the landscape level. Such factors are: location, size and shape of gaps in relation to most vulnerable stands, the length of the stand boundary section adjoining gaps (i.e. vulnerable edges) and edge stand characteristics. Therefore, for each case study, the creation of the landscape and the evaluation of wind damage were iterated 100 times. Thus, the mean, standard deviation (stdev) and coefficient of variation $(\mathrm{CV} \%=$ stdev/mean $\times 100 \%)$ ) of the 100 iterations were computed for each case study in order to compare the findings between different landscape compositions.

\subsection{Computation of the risk of wind damage based on HWIND model computations}

In this work the risk of wind damage to tree stands was evaluated based on critical wind speed computations by HWIND, a mechanistic wind damage model (Peltola et al., 1999). This model can describe the mechanistic behavior of Scots pine and Norway spruce trees under wind loading at forest edges. In the model, a tree is assumed to be uprooted if the maximum bending moment (due to forces by wind and gravity) exceeds the resistance of the root-soil plate (Peltola et al., 1999). Similarly, the stem is assumed to be broken if the breaking stress exceeds the critical value of the modulus of rupture (Peltola et al., 1999; Petty and Swain, 1985; Petty and Worrel, 1981). This makes it possible to calculate the minimum wind speed needed for uprooting or stem breakage (critical wind speed). The model outputs the mean critical wind speeds, lasting for one hour (transformed into $10 \mathrm{mins}$ averages in this work by multiplier of 1.1) at $10 \mathrm{~m}$ above ground level, at which trees are uprooted and broken at the downwind stand edge of open areas such as a new clear cut.

The inputs of the model are tree species, average tree height, average diameter at breast height (DBH) and stand density, in addition to distance from the forest edge and gap size (i.e. length of the gap in the direction of wind). The properties of the HWIND model, its parameters, inputs and the validity of its outputs for podzol soil conditions in Finland, have been discussed in detail by Peltola et al. (1999), Gardiner et al. (2000) and Talkkari et al. (2000).

In this work, we also calculated the critical wind speeds for downwind stand edges of the gaps, which represented open non-forest areas (e.g. water areas, open fields), clearcuts and seedling stands with an average tree height of less than 


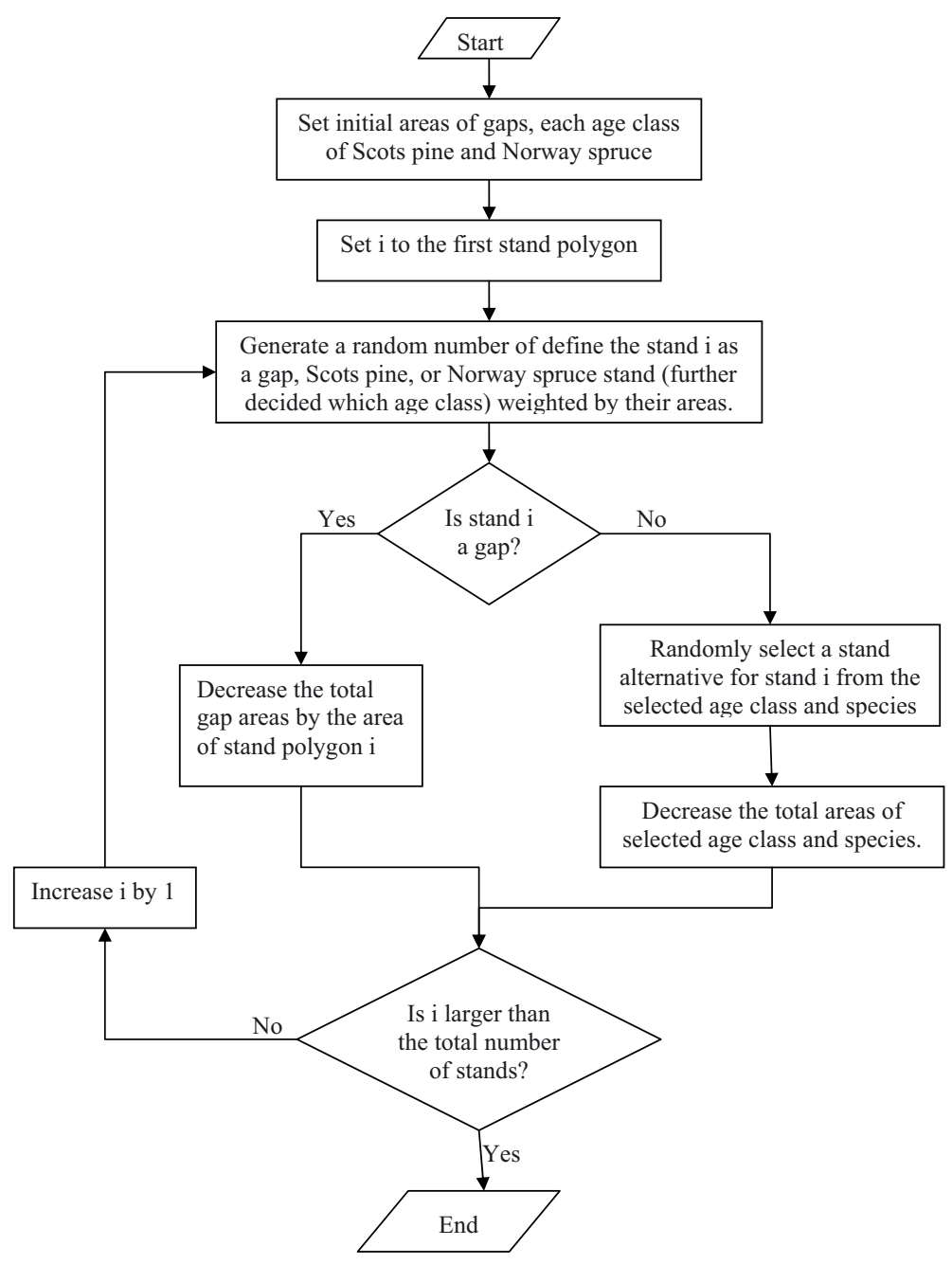

Figure 1. The flow of landscape generation.

$2 \mathrm{~m}$. Moreover, the gap diameter at wind direction was assumed to be 10 times the average tree height at the stand edge, which provides the maximum risk (i.e. the lowest critical wind speeds) in regard to gap size (Peltola et al., 1999). If we would have used instead, for example, 5 times the average tree height at the stand edge as gap size, the critical wind speeds would have been on average $20 \%$ higher (see Peltola et al. 1999). The critical wind speeds are calculated in HWIND only for stands having an average tree height $>10 \mathrm{~m}$ (and DBH $>10 \mathrm{~cm}$ ) located at downwind edge of an open area (Peltola et al., 1999). The current version of the model is not capable of considering accurately any risks for smaller trees because of limitations of the tree allometry functions used.

The critical wind speeds calculated by the HWIND model could not, however, be used directly to evaluate the amount of forest stands, and their edges, at risk. However, we used them as input for a linear utility function to estimate the risk as was also done in previous work by Zeng et al. (2009). In this context, the trees with critical speeds $<15 \mathrm{~m} \mathrm{~s}^{-1}$ had a risk probability of 1 , whereas the trees with critical wind speeds $>30 \mathrm{~m} \mathrm{~s}^{-1}$ had a risk probability of 0 . Between these wind speeds the risk was interpolated with a linear utility function (Fig. 2). These thresholds for the wind speeds were selected based on the fact that in recent storms causing damages in Finnish conditions, the mean wind speeds of 2-10 min have typically ranged between 14 and $27 \mathrm{~m} \mathrm{~s}^{-1}$ (with corresponding gust speeds of 20-40 $\mathrm{m} \mathrm{s}^{-1}$ ) at $10 \mathrm{~m}$ above ground level (FMI, 2003; Laiho, 1987; Pellikka and Järvenpää, 2003; Talkkari et al., 2000).

In principle, the level of risk can be assessed, for example, according to the number of stands, their area and length of edges at risk (Zeng et al., 2004). Since the stands located especially at new edges (gaps) have the most potential to be damaged in Finnish conditions, the length of edges at risk was used in this work to represent the level of risk of wind damage at the landscape level. It also usually represents the first occurrence of the wind damage in the forest. In order to calculate the total length of edges at risk for each stand adjoining a gap (edge stand), the following steps were done: firstly, the critical wind speeds were computed for each edge using the HWIND model. Secondly, these critical wind speeds were used as input to the utility function. Finally, the total length of edges at risk 


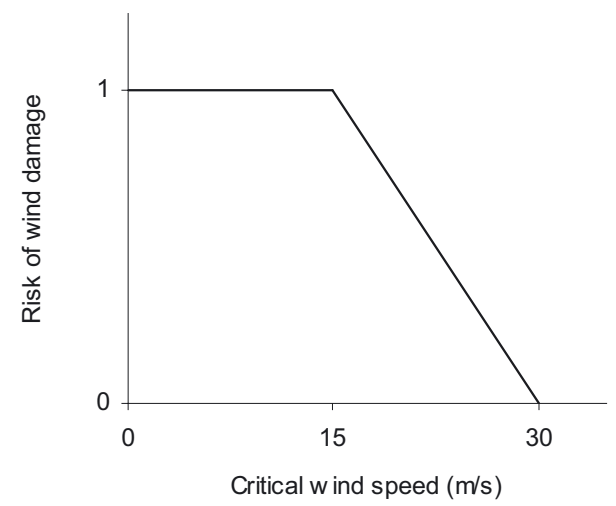

Figure 2. Utility function for the risk of wind damage.

were computed by multiplying the risk utility value with the corresponding length of the boundary section located between edge stand and gap for each stand edge.

\section{RESULTS}

We found that even a small increase in the proportion of gap areas significantly increased the total length of edges at risk, regardless of the age class distribution of the forest (Fig. 3). For example, when the proportion of gap areas increased from $10 \%$ to $20 \%$, the length of edges at risk increased by $77-80 \%$ for different age class distributions. However, the average increment of the length of edges at risk gradually slowed down with the increment of the proportion of gap areas. The total length of edges at risk reached, on average, maximum values when about $50 \%$ of the landscape was open gaps (Fig. 3a), after this point the risk started to decrease due to general decrease of forest margins.

The total length of edges at risk increased especially with the increase in the share of mature stands relative to all forest stands (see Fig. 3a). The forest with right-skewed age distribution (most mature stands) had, in general, the most edges at risk, while the left-skewed distribution least (least mature stands). Thus, an increase in the proportion of older forest stands would significantly increase the susceptibility of the landscape to wind damage.

Generally speaking our results also showed relatively small variation around the mean results between different iterations (stdev and $\mathrm{CV} \%$ ) regardless of proportion of gaps and forest structure (see Figs. 3b, c), but the standard deviation increased with the increment of the proportion of gap areas. The landscape with forest with equally distributed age classes had, in general, a larger variation within the 100 iterations than the other age class distributions. This might be because it had more complicated forest structure at the landscape level. On the other hand, the forest with left-skewed age class distribution had relatively small standard deviation, however it had large $\mathrm{CV} \%$, which might be because the risk of wind damage was very small and even a small change could induce large changes in $\mathrm{CV} \%$. (a)

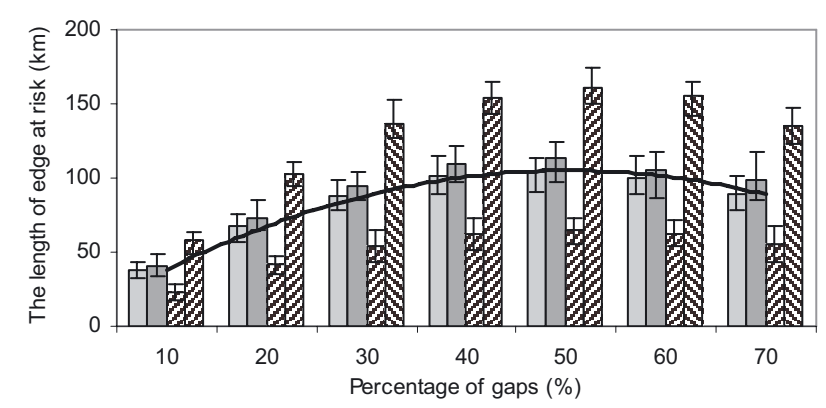

(b)

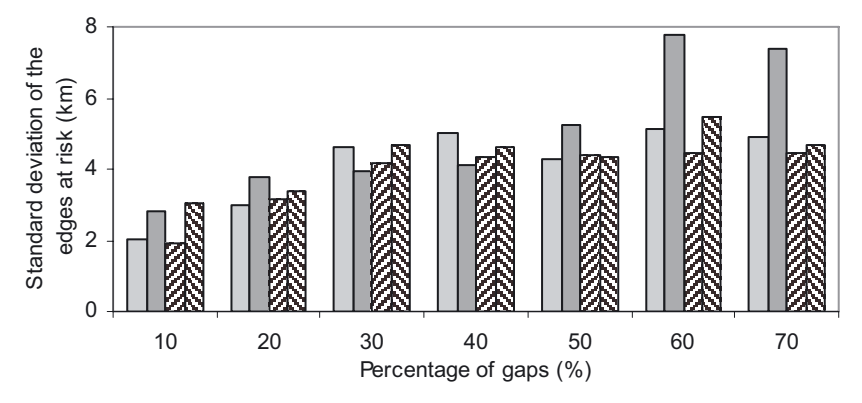

(c)

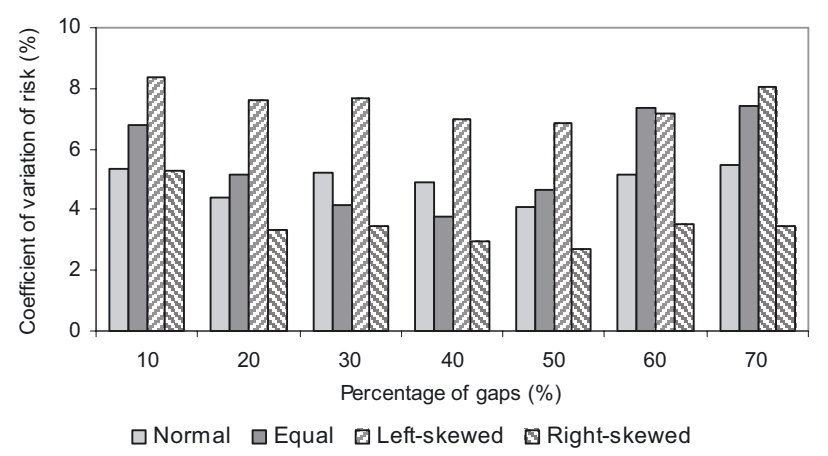

Figure 3. The average for total length of edges at risk (a), its standard deviation (b), and coefficient of variation, CV within the 100 iterations(c). The curve in (a) is the trend of the mean values.

When changing the proportion of gaps in the area, it was also found that the total length of edges at risk (m) per unit area (hectare) increased when the proportion of gap areas were increased (Fig. 4). Each $10 \%$ increment of gap areas induced $16-102 \%$ increase in the length of edges at risk. This means that the increment of open gaps would always increase the proportion of stands to be located at the edges and induce more risks.

In our work, the risk of damage was also sensitive to the proportion of older (mature) stands in a forest. For example, when taking as a reference a forest with equal age class distribution (25\% of forest area for each age class group) and 30\% of gaps, if the proportion of mature stands was decreased from $25 \%$ to $10 \%$ of the total forest area (increasing the remaining 


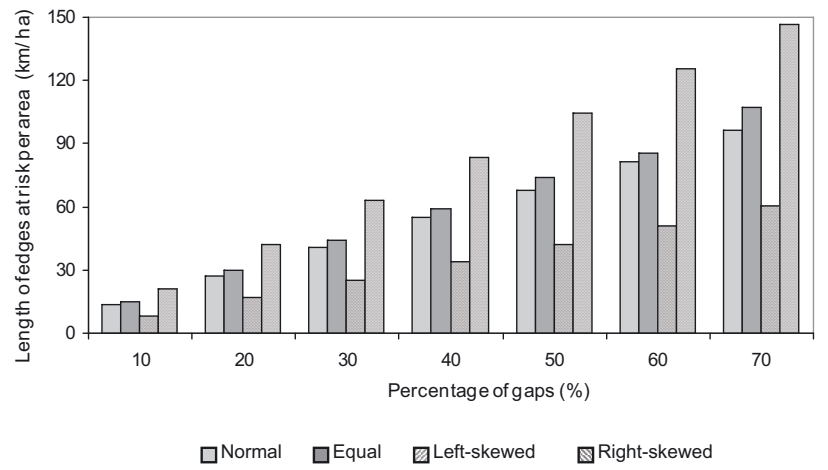

Figure 4. The density of the risk of wind damage of the forest, i.e. the length of edges at risk per hectare of forest.

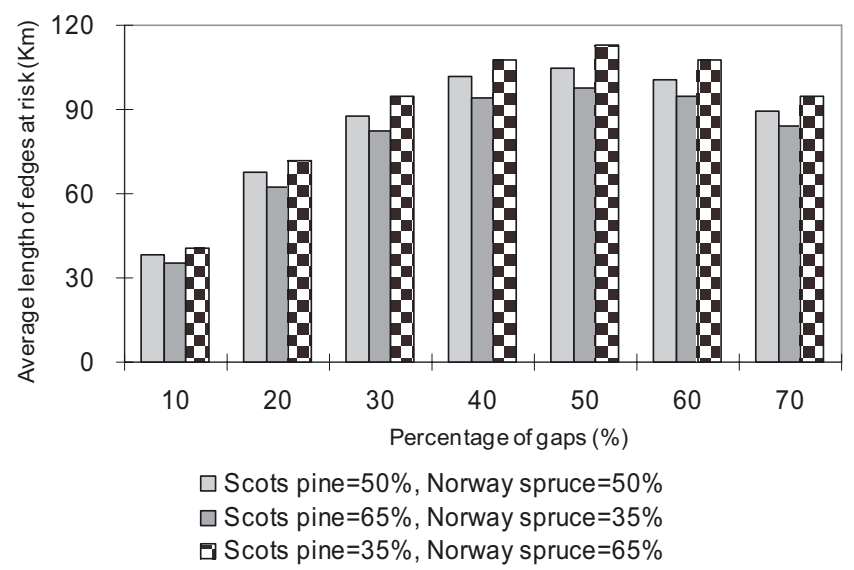

Figure 5. The length of edges at risk when changing the forest species composition. The forest with normal distributed age classes was used in this case study.

age class groups to $30 \%$ of the total forest area), the total length of edges at risk decreased by $16 \%$. While, if the mature stand proportion was increased from $25 \%$ to $40 \%$ (and the remaining age classes decreased to $20 \%$ each), the total length of edges at risk increased by $19 \%$. Thus, the changes to the proportion of mature stands had a large impact on the length of edges at risk.

The species composition also similarly influenced the length of edges at risk at the landscape level. Taking as a reference a landscape with a normally distributed age class, when the area of Norway spruce stands was decreased from 50\% to $35 \%$ of the total forest area and that of Scots pine correspondingly increased from $50 \%$ to $65 \%$, the edges at risk decreased by $7 \%$ compared to the forest consisting of $50 \%$ of each species (Fig. 5). On the other hand, the length of edges at risk increased by $7 \%$ when the area of Norway spruce was increased by $15 \%$. This pattern was followed despite the variation in proportion range of gap areas analyzed. The effect of changes in species composition between Norway spruce and Scots pine, however, was much smaller than the influence of the proportion of mature stands and gap areas.

\section{DISCUSSION AND CONCLUSION}

Previously many authors have analyzed the impacts of gap characteristics (e.g. its size and perimeter), as well as the presence of old stands, on the risk of wind damage at downwind stand edges of open areas (e.g. Blennow and Sallnäs 2004; Elling and Verry, 1978; Lanquaye-Opoku and Mitchell 2005; Neustein, 1965; Stacey et al., 1994; Venäläinen et al., 2004; Zeng et al., 2004; 2006, 2007).

However, no systematic studies exist on how sensitive the risk of wind damage is at the landscape level regarding changes in forest structure; in terms of relative proportion of gap area, age class distribution and/or tree species composition. In this sense, our work represents one of the first attempts to study the sensitivity of forest structure (i.e. gap area, age class distribution and species composition) regarding the risk of wind damage at the landscape level. In our work, we analyzed how the forest structure affected the risk of wind damage in terms of length of stand edges at risk using: (i) a mechanistic wind damage model HWIND and (ii) Monte Carlo simulation as a basis for such analyses. In addition GIS software (ArcGIS) was used to provide the topology between stands and edges making it possible to use vector data in the analysis. GIS provides information regarding the neighboring stands and the length of edges between these stands, which is necessary for calculating the length of edges at risk.

We analyzed the effects of forest fragmentation on the risk of damage based on the use of theoretically generated forest landscapes, as well as on the use of a linear risk utility function as was also done in previous work by Zeng et al. (2009). This approach is a simplification of reality and could overestimate the actual risk of occurrence of critical wind speeds at our study site. Therefore, in order to avoid overestimation of the risk, regardless of wind speed expected, our risk consideration should be taken as relative risk instead of actual risk (which is a function of wind climate in reality). Unfortunately, the actual probabilities of the range of critical wind speeds observed were not available for our study site. Nevertheless, even though our work could be considered as being theoretical, the findings are valuable for forest managers; as it enables the acquisition of knowledge and valuable information for further use in forest planning which will be important for risk consideration at the landscape level.

In principle, topography could induce fragmentation, and even have a more important role than the fragmentation caused by forest management, especially in hilly areas. However, because our study site was relatively flat we did not consider this in our work. Also, in general, in Finnish conditions clear cutting could be taken as a key factor to forest fragmentation because Finland is a relatively flat country. In reality, it is also very difficult to systematically study the effect of topography on fragmentation, because it also directly affects the wind flow (direction, speed).

Overall, we found that any increase in the proportion of gap areas, at a landscape level, notably increased the risk of wind damage in terms of total length of stand edges at risk, regardless of age class distribution. The risk of wind damage increased until $50 \%$ of the landscape area was covered by open 
gaps. This was the case even though the total forested area was decreasing with the increment of the gap areas. Thus, if it is possible to avoid unnecessary increase of gaps and new stand edges, the risk of wind damage on a landscape level could possibly be reduced.

On the other hand, the age structure of a forest also affects the risk of wind damage at forest edges as was also demonstrated in our work. Previously, Garcia-Gonzalo et al. (2007) also used the same initial stand structures, when analyzing the impacts of forest landscape structure and management on timber production in the boreal forest ecosystem over time. They observed that the initial age class distribution also had a relatively large influence on timber production (up to 20\% difference), which we did not consider in our study. Though this also underlines the theoretical findings of our work, our static approach allows us to evaluate how the risk of wind damage would be increased or decreased when doing new clear cuts (i.e. creating new gap areas), which is very important for foresters and forest managers as clearcuts and thinning instantly change the stability of surrounding stands. This information may be used to properly schedule the clear-cuts over a landscape level, which will allow the simultaneous consideration of objectives of timber production and reduction of risks by wind without a major reduction in timber production in a forest management unit as demonstrated by Zeng et al. (2007).

Because older stands are most vulnerable to be damaged (Peltola et al., 1999), a high proportion of old stands, especially at the downwind stand edges of open gaps (or next to young seedling stands), will induce high risk of wind-induced damage (Zeng et al., 2006), as was also demonstrated in this study. In this context, the risk of wind damage could be reduced at the landscape level through the proper timing of harvesting of the most vulnerable older stands. On the other hand, poor placement of clearcuts may produce a more fragmented landscape and increase the number of vulnerable stands adjoining gaps. In this context, Zeng et al. (2007) previously suggested the use of clustered open gaps (e.g. by clear-cut) and harvesting old edge stands to smooth the landscape regarding tree height differences of edge stands and to avoid the creation of new openings at the edges of old stands.

We also found that changes in the mixture of species of Scots pine and Norway spruce had some, though comparatively less, effect on the total length of edges at risk than open gaps and forest age structure. This means that forest structure dominated by Norway spruce stands would be only slightly more vulnerable to damage than those dominated by Scots pine, for the same forest age structure. The risk of wind damage was simulated in this work only for a forest with a mixture of Scots pine and Norway spruce, which are the two most important commercial species in Finland. On the other hand, compared to conifers, deciduous species, such as birch (Betula spp.), have shown significantly lower risk to wind damage in Finnish conditions due to the fact that most storms in Finland occur from late autumn to early spring when deciduous species have no leaves and consequently experience much less wind loading.

If the gaps (sizes and occurrence) and age structure of the forest were fixed, there still existed small variations in the length of edges at risk. These variations could be explained by the factors which were not fixed in the analysis, such as: (1) location and size of gaps in relation to most vulnerable edge stands; (2) length of vulnerable edge in each stand (the boundary section between the edge stand and gap); and (3) stand characteristics in selected stand alternatives even within the same age class of the same species. These random variations also indicated that the risks vary to some extent depending on spatial and temporal configuration of landscape (gaps and forest stands) with fixed existence of open gap areas, age structure and species composition.

To conclude, the relative increment of gap area and/or ages of forest stands (especially older stands) in a forest ecosystem, in general, could be expected to significantly affect the risk of wind damage at the landscape level in addition to topography, which we did not consider in our work. Therefore, the best way to decrease the risk of wind damage would be avoiding unnecessary open gaps, especially at the edges of older stands, punctual harvesting of the older stands with the highest risk and increasing the composition of deciduous species or Scots pine as a substitute for Norway spruce in regeneration, if possible. However, the necessary actions needed for risk consideration at a landscape level largely depend on the prevailing forest structure in addition to wind climate and topography of the site.

Acknowledgements: This work is related to the research carried out at the Centre of Excellence for Forest Ecology and Management (Project No. 64308), led by Prof. Seppo Kellomäki, University of Joensuu in 2000-2005, and the project on "Silvicultural strategies for managing wind and snow-induced risks in forestry" (SilviRisks, Project No. 52724), funded by the Academy of Finland (2001-2004). This work has been finalized under the project on "Impacts of temporal and spatial variability of critical weather events and forest management on the risk of wind and snow induced damage in forest stands (Project No. 121623)", led by Dr Heli Peltola, University of Joensuu, Faculty of Forest Sciences (funded by the Academy of Finland, 2008-2010). The authors would like to thank Forest Centre Pohjois-Savo, for providing the forest stand data (X-forest-data) for the area.

\section{REFERENCES}

Ancelin P., Courbaud B., and Fourcaud T., 2004. Development of an individual tree-based mechanical model to predict wind damage within forest stands. For. Ecol. Manage. 203: 101-121.

Blennow K. and Sallnäs O., 2004. WINDA - a system of models for assessing the probability of wind damage to forest stands within a landscape. Ecol. Model. 175: 87-99.

Copeland J.H., Pielke R.A., and Kittel T.G.F., 1996. Potential climatic impacts on vegetation change: a regional modelling study. J. Geophys. Res. 101(D3): 7409-7418.

Coutts M.P., 1986. Components of tree stability in Sitka spruce on peaty gley soil. Forestry 59: 173-197.

Elling A.E. and Verry E.S., 1978. Predicting wind-caused mortality in strip-cut stands of peatland Black spruce. For. Chron. 54: 249-252.

FMI, Finnish Meteorological Institute. 2003. Weather statistics of the storms in Finland [online], available from http://www. ilmatieteenlaitos.fi/saa/tilastot_21.html [cited 16 March 2003]. 
Garcia-Gonzalo, J., Peltola, H., Zubizarreta-Gerendiain, A., and Kellomäki, S. 2007. Impacts of forest landscape structure and management on timber production and carbon stocks in the boreal forest ecosystem under changing climate. For. Ecol. Manage. 241: 243-257.

Gardiner B.A., Stacey G.R., Belcher R.E., and Wood C.J., 1997. Field and wind tunnel assessments of the implications of respacing and thinning for tree stability. Forestry 70: 233-252.

Gardiner B.A., Peltola H., and Kellomäki S., 2000. Comparison of two models for predicting the critical wind speeds required to damage coniferous trees. Ecol. Model. 129: 1-23.

Laiho O., 1987. Metsiköiden alttius tuulituhoille Etelä-Suomessa. [Susceptibility of forest stands to wind throw in southern Finland.] Folia For. 706: 1-24 (in Finnish with English summary).

Lanquaye-Opoku, N. and Mitchell, S.J., 2005. Portability of stand-level empirical windthrow risk models. For. Ecol. Manage. 216: 134-148

McNaughton K.G., 1989. Micrometeorology of shelter belts and forest edges. Phil. Trans. R. Soc. Lond. B 324: 351-368.

Mayer H., 1989. Windthrow. Phil. Trans. R. Soc. Lond. B 324: 267-281.

Neustein S.A., 1965. Windthrow on the margins of various sizes of felling area. Report on forest research for the year ended March 1964, Forestry Commission pp. 166-171.

Pellikka P. and Järvenpää E., 2003. Forest stand characteristics and wind and snow induced forest damage in boreal forest. Proceedings of the International Conference on Wind Effects on Trees, held in September 16-18, 2003, University of Karlsruhe, Germany, p. 8.

Peltola H., Kellomäki S., Väisänen H., and Ikonen V.P., 1999. A mechanistic model for assessing the risk of wind and snow damage to single trees and stands of Scots pine, Norway spruce, and birch. Can. J. For. Res. 29: 647-661.

Peltola H., Kellomäki S., Hassinen A., and Granander M., 2000. Mechanical stability of Scots pine, Norway spruce and birch: an analysis of tree-pulling experiments in Finland. For. Ecol. Manage. 135: 143-153.

Petty J.A. and Swain C., 1985. Factors influencing stem breakage of conifers in high winds. Forestry 58: 75-85.
Petty J.A. and Worrell R., 1981. Stability of coniferous tree stems in relation to damage by snow. Forestry 54: 115-128.

Quine C.P., 2000. Estimation of mean wind climate and probability of strong winds for wind risk assessment. Forestry 73: 247-258.

Ravn H.P., 1985. Expansion of the populations of Ips typographus (L.) (Coleoptera, Scolytidae) and their local dispersal following gale disaster in Denmark. Z. Angew. Entomol. 99: 27-33.

Stacey G.R., Belcher R.E., Wood C.J., and Gardiner B.A., 1994. Wind flows and forces in a model spruce forest. Boundary-Layer Meteorol. 69: 311-334.

Talkkari A., Peltola H., Kellomäki S., and Strandman H., 2000. Integration of component models from the tree, stand and regional levels to assess the risk of wind damage at forest margins. For. Ecol. Manage. 135: 303-313.

UNECE/FAO, 2000. Forest products annual market review. United Nations Economic Commission for Europe (Geneva), Food and Agriculture Organization of the United Nations (Rome).

Venäläinen A., Zeng H., Peltola H., Talkkari A., Strandman H., and Kellomäki S., 2004. Simulations of the influence of forest management on wind climate on a regional scale. Agric. For. Meteorol. 123: $149-158$.

Zeng H., Peltola H., Talkkari A., Venäläinen A., Strandman H., Kellomäki S., and Wang K., 2004. Influence of clear-cutting on the risk of wind damage at forest edges. For. Ecol. Manage. 203: 77-88.

Zeng H., Peltola H., Talkkari A., Strandman H., Venäläinen A., Wang K., and Kellomäki S., 2006. Simulations of the influence of clearcuttings on the risk of wind damage on a regional scale over a 20 year period. Can. J. For. Res. 36: 2247-2258.

Zeng H., Pukkala T., and Peltola H., 2007. The use of heuristic optimization in risk management of wind damage in forest planning. For. Ecol. Manage. 241: 189-199.

Zeng H., Peltola H., Väisänen H., and Kellomäki S. 2009. The effects of fragmentation on the susceptibility of a boreal forest ecosystem to wind damage. For. Ecol. Manage. 257: 1165-1173. 